\title{
Sibling Snapshots: Living with Youth who have Autism or Down Syndrome
}

\author{
Jessica L. Rosemann ${ }^{1}$, Aimee L. Latta Palicharla ${ }^{2}$, Tammy Rampton ${ }^{3}$, Barbara Mandleco ${ }^{4,}$, \\ Tina T. Dyches ${ }^{5}$, and Donna Freeborn ${ }^{4}$ \\ ${ }^{1}$ Primary Children's Medical Center, Salt Lake City, UT; ${ }^{2}$ Beth Israel Deaconess Medical Center, Boston MA; \\ ${ }^{3} 13267$ W Foliage Ct, Boise, ID; ${ }^{4}$ College of Nursing, Brigham Young University, Provo, UT and ${ }^{5}$ McKay \\ School of Education, Brigham Young University, Provo, UT, USA
}

\begin{abstract}
This study used photography to capture important symbols in the lives of 14 siblings of 13 youth with autism (ASD) and 16 siblings of 15 youth with Down syndrome (DS), and then determine if there were differences in photographs taken according to type of developmental disability, age, and gender of the sibling. Photographs were divided into two categories: photographs of people, including family and non-family members, and non-people, including personal items/objects, animals, and buildings/scenery. Siblings of youth with DS took a higher percentage of photographs of people and family members than siblings of youth with ASD. There were also differences according to age and gender in the people/non people and within family photographs. The 7-9-year-olds took a higher percentage of snapshots of typically developing siblings and him/herself whereas the 10-12-year-olds and the 13-16-year-olds took a higher percentage of photographs of the youth with the disability than the younger age group. Sisters took a higher proportion of people photographs than brothers, while brothers took a higher proportion of family photographs than sisters. Results validate the importance of gathering data in an open-ended manner directly from young people, confirm the use of photography as a method of facilitating communication with young people about important symbols in their lives, and indicate there are differences in the percentage of photographs taken of people/non people and family/non family according to disability, age, and gender of siblings.
\end{abstract}

Keywords: Autism, Autism spectrum disorder, Down syndrome, Siblings, Photo elicitation.

\section{INTRODUCTION}

Living with a young person with a developmental disability (DD) can be stressful [1,2], perhaps because families experience incongruence between experiences with the young person and what they hear from health care providers, as well as ambiguous diagnoses, variable severities, and unclear durations. If the youth has autism spectrum disorder (ASD), the young person's repertoire of restrictive/repetitive behaviors and communication difficulties are additional sources of stress for all family members including siblings who may experience adjustment/coping issues or impaired relationships [3-9]. If the youth has Down syndrome (DS), families face not only unique responsibilities and issues related to developmental challenges, but also health challenges accompanying the syndrome. Siblings of youth with DS are also affected and may demonstrate problems with adaptation [10-12]. They often see their parents as being more lenient and giving extra attention to their DS sibling $[13,14]$. Clearly, families raising young people with ASD or DS experience unique stres-

Address correspondence to Barbara Mandleco,

E-mail: barbara.mandleco@gmail.com sors and challenges in addition to those faced by families raising typically developing youth (TDY).

Research investigating experiences of siblings living with a young person with DS or ASD has frequently relied on data provided by parents, teachers, or counselors [6,15-18]. Topics of study centered on behavior problems, emotional adjustment, participation in extracurricular activities, social skills, peer relations, or personality characteristics, with little attention paid to sibling perceptions of living with a young person with ASD or DS $[11,15,17,19-21]$.

When siblings participated in research about experiences, information was often obtained from written questionnaires developed by adults, or interviews conducted by adults, which may not be appropriate for siblings' developmental levels $[4,11,22-24]$. A method encouraging responses without adult intervention and allowing freedom of expression/thought is preferable while gathering data directly from siblings.

Methods suitable for gathering data from young populations include sentence completion lists, video cameras, daily diaries, and spontaneous 
drawings, [23,25-27]. Another suitable method is photo elicitation, which can provide insights into young people's lives and generate discussions about photographs [28-36]. With this study, we sought to examine photo elicitation as a method of capturing important symbols in the lives of siblings living with a young person who has ASD or DS, identify themes emerging from the photographs, use sibling narratives about the photographs to describe the identified themes, and then compare the themes according to age, gender, and disability. We chose this method because little information exists in the literature from this population using photo elicitation. In addition, research using this method can provide helpful information about these siblings' lives.

ASD describes a complex, lifelong, developmental disorder characterized by deficits in communication and restrictive/repetitive activities affecting youngsters before three years of age $[37,38]$. Communication skills range from unusual or overly-formal speech and language patterns to being completely non-verbal $[39,40]$. Youth with ASD may also display inappropriate emotional reactions, abnormal responses to sensory experiences, deficiencies in social relationships, and social isolation, which impact youthful siblings $[11,20,38]$. Siblings raised with a young person with ASD can be affected by their brother/sister's repetitive, violent, obsessive behaviors, impaired communication skills, and antisocial/disruptive actions $[4,11,22,41-43]$.

Often these effects relate to interactions siblings have with the young person with ASD. For example, siblings are often aggressive in interactions and negative in perceptions of their relationships with the youth with ASD, especially when the young person disturbs them $[15,17,21,43,44]$. Siblings also report parents give more attention to the young person with ASD, which limits family interactions and negatively impacts sibling relationships [11,45-47]. Siblings of ASD youth sometimes show social deficits compared to siblings of youth with other disabilities or TDY $[6,22,48]$. In addition, they may have academic difficulties or higher rates of adjustment/internalizing problems compared to controls $[6,15-18,49]$.
Research also identifies positive outcomes for siblings who lived with a young person with ASD. For example, some siblings show less competition/ quarreling and more admiration in their sibling relationships than TDY [43,50]. They may also display more emotional, behavioral, or intellectual successes than controls, assume adult responsibilities at an early age, and exhibit more maturity $[20,22]$. Finally, other positive effects include intense emotional ties, strong feelings of affection/comradeship, and more accepting/supportive behaviors than those who do not live with a young person with ASD [22].

DS, a chromosomal abnormality affecting more than 400,000 people in the United States, occurs in one out of 691 births [51]. Youth with DS have similar physical features, but varied intellectual capacities [51,52]. Most young people with DS have appropriate social skills, but severity varies, and the syndrome accounts for about one third of moderate to severe cases of intellectual disability $[52,53]$. Youth with DS can be described as cheerful, positive in their relations with others, eventempered, and affectionate [54-56]. These youth exhibit strong pro-social behavior and conversational skills when compared to youth with other cognitive disabilities [56]. Other research suggests these individuals have higher levels of adaptive behavior and lower levels of maladaptive behavior when compared to those with other DD $[57,58]$. Most mothers describe their youngsters with DS as having an outgoing/active temperament rather than being withdrawn, disruptive, or passive [59]. When negative behaviors are observed they include hyperactivity, stubbornness, demanding attention, difficulty sleeping, disobedience, aggression, inattentiveness, and impulsivity $[55,56,60$, 61].

Siblings of young people with DS exhibit both negative and positive effects. Early research suggested siblings were negatively impacted and experienced higher levels of depression, loneliness, embarrassment, jealousy, anxiety, and aggression, as well as lower perceived self-competence when compared to siblings of youth who did not have a disability [12,62-65]. However, more recent research suggests siblings are positively impacted 
by living with a child/adolescent with DS $[13,14$, $66,67]$. Positive effects include increased understanding, intelligence, altruism, independence, tolerance, and compassion towards others [14]. Siblings also reported positive sibling relationships, viewed the relationship as an important part of their life, and enjoyed time spent together $[13,41,68]$. Other investigators noted these siblings admired the child/adolescent more than did siblings of children/adolescents with autism or TDY [41].

Researchers use photo elicitation to document/ talk about life experiences when participants are interviewed about photographs taken [69-72]. Photo elicitation is also an effective and inexpensive method of gathering data from reticent or immature populations because it allows them to take part in research when they may not be able to discuss abstract ideas [32,34,36,73,74]. The method was used with siblings and young people experiencing asthma, cystic fibrosis, diabetes, mobility impairments, cancer, developmental disabilities, autism, and Down syndrome, as well as homeless youngsters, school-aged youth, and preschoolers [28-30,33,35,69,75-79]. Photo elicitation techniques were also used to study attention deficit disorder in Canadian youth, Irish immigrant young people, and South African adolescents orphaned by HIVIAIDS [36,80,81]. Samoan youngsters living in New Zealand used cameras to show reading/writing done outside the school setting, displaced/refugee youths living in Colombia and the United States illustrated life experiences by using cameras, and youth with chronic illnesses living in the United Kingdom documented their lives with photos $[32,34,69]$. In summary, photo elicitation improves communication between young participants and researchers, assists investigators understand human experiences, is an effective method of gathering data, and creates a comfortable atmosphere [82].

This study sought answers to the following questions:

- What themes/subthemes can be identified from photographs taken by siblings of youth with ASD or DS that reflect what is important/significant in their lives ?

- Are there differences in the photograph themes/subthemes according to gender, age, and disability?

\section{METHOD}

The research was part of a larger institutional review board-approved study examining family adaptation to living with a young person with disabilities or chronic conditions. Inclusion criteria were that siblings needed to be at least seven years of age, capable of speaking/understanding the English language, able to take photographs with a disposable camera, and willing to talk about their photographs in an open-ended interview.

Fourteen (9 brothers, 5 sisters) siblings of 13 youth with ASD and 16 (6 brothers, 10 sisters) siblings of 15 youth with DS participated. Families living in a metropolitan area of a western state were recruited by fliers, and word of mouth. All but one participant lived in two-parent homes and most families were raising at least two other children/adolescents. Over half the families earned more than $\$ 50,000$ per year. Table 1 presents additional demographics.

Parents were contacted by telephone to explain the study and set up the first of two home visits. Parent consent and child/adolescent assent were obtained during this visit and then siblings were asked to photograph what was important to them over the next two weeks with a $35 \mathrm{~mm}$ disposable

\section{Table 1: Demographics}

\begin{tabular}{|lll|}
\hline & \multicolumn{1}{|c|}{ Autism Spectrum Disorder } & \multicolumn{1}{c|}{ Down Syndrome } \\
\hline Sibling age (SD); range & 10.79 years (2.29); 8-16 years & $10.89(2.23) ; 7-15$ years \\
Youth with DD age (SD); range & 6.85 years (2.23); 3-10 years & 7.34 (4.37); 1-17 years \\
Gender of sibling & 9 brothers, 5 sisters & 6 brothers, 10 sisters \\
Gender of youth with DD & 9 male; 4 females & 6 male; 9 female \\
\hline
\end{tabular}


camera with built-in-flash containing 24-27 color exposures. If needed, information on using cameras was provided. Parents were told siblings should use cameras voluntarily. Parents could remind participants to take snapshots, but not suggest taking certain photographs. Cameras were picked up two weeks later and a second appointment made to discuss photographs with the siblings. The one-on-one interviews discussing snapshots were audio recorded and held in private places selected by siblings. After identifying images, siblings told investigators why each photograph was important. Participants were encouraged to freely discuss each photograph in the order taken. Clarifying questions were asked as needed. Siblings received a set of their photographs. The interviews were transcribed verbatim.

Photographs were sorted into categories by individual investigators based on sibling descriptions. Investigators then verified/compared their analyses and identified preliminary themes through open coding, before collapsing patterns, creating sub-themes, and determining final themes/sub themes. Direct quotations were then chosen from transcribed interviews illustrating why participants' said photographs were important. Field notes explained/clarified interview data. See Table 2 for a list of themes, sub-themes, and illustrative quotations.

Table 2: Theme/Sub theme, Descriptions, and Quotation Examples

\begin{tabular}{|c|c|}
\hline Theme/Sub Theme & Examples \\
\hline \multicolumn{2}{|l|}{ PEOPLE } \\
\hline \multicolumn{2}{|l|}{ Family } \\
\hline Young person with DD & $\begin{array}{l}\text { "He helps me understand things ... like I don't look at people that need, } \\
\text { like handicaps, the same." "I like that he's always so happy." }\end{array}$ \\
\hline TDS & "Because he sets a good example." \\
\hline $\begin{array}{l}\text { Mixed immediate family members } \\
\text { (Brothers, sisters, parents) }\end{array}$ & $\begin{array}{l}\text { "It's of my family, and I took it because they always help me when I'm in } \\
\text { trouble." }\end{array}$ \\
\hline Parents & $\begin{array}{l}\text { "This is a picture of my mom . . .um it means a lot because she's my } \\
\text { mom." } \\
\text { "And that's my dad. And I took a picture of him because I love him and } \\
\text { he's really fun." }\end{array}$ \\
\hline Self & ". . . cause I'm pretty important to myself" \\
\hline $\begin{array}{l}\text { Extended family members (Aunts, } \\
\text { uncles, cousins, grandparents) }\end{array}$ & $\begin{array}{l}\text { "Alright, this is my cousin, Sarah, and we just, we always play together } \\
\text { and stuff . . and she's like one of my best friends." } \\
\text { "Because I love them ..." (talking about grandparents) }\end{array}$ \\
\hline $\begin{array}{l}\text { Non-family (Neighbors, friends, } \\
\text { teachers, therapists) }\end{array}$ & $\begin{array}{l}\text { "That's my friend ... she's my best friend ... [ [my friends] . . . they're the } \\
\text { only ones that I can really be weird with." } \\
\text { "... because she always helps me pick out real good books" (talking } \\
\text { about the school librarian] }\end{array}$ \\
\hline \multicolumn{2}{|l|}{ NON-PEOPLE } \\
\hline $\begin{array}{l}\text { Objects/Personal Items (Cars, } \\
\text { household items, CDs, books, } \\
\text { toys, athletic items) }\end{array}$ & $\begin{array}{l}\text { "I like books because they give me something when I'm really bored, like } \\
\text { when there's nothing to do, like when I can't play on my computer, and I } \\
\text { can't go outside, and none of my friends can play, and I've done all my } \\
\text { homework, I've watched all the shows I can. So, I decided to read books." }\end{array}$ \\
\hline Animals & "It's of my dog, and I took it because, well, he's always fun to play with." \\
\hline $\begin{array}{l}\text { Buildings/Scenery (Houses, } \\
\text { rooms in houses, churches, } \\
\text { schools) }\end{array}$ & $\begin{array}{l}\text { "I would have to move away if I didn't have it . . . I would be living on the } \\
\text { street."... (talking about his house) } \\
\text { "That's of my school because that's where I learn what happens, what's } \\
\text { going on" }\end{array}$ \\
\hline
\end{tabular}


The number and percentage of snapshots taken in each theme/sub-theme were determined. Chisquare goodness of fit analyses were conducted to determine if similarities existed in the percentage of photographs taken according to type of disability, gender, age, gender/disability, and age/disability. For age analyses, siblings were divided into three age groups: 7-9-year-olds, 10-12year-olds, and 13-16-year-olds. Age ranges are based on both Piaget's cognitive stage of development and Vygotsky's sociocultural theory of development $[82,83]$.

\section{RESULT}

Siblings of youth with DD took 729 photographs. Twenty-five were eliminated because they were blurry, or participants did not remember taking the photograph. From the remaining 704 photographs, two major themes emerged: people and non-people. Most photographs contained people ( $N=475 ; 67 \%)$. Refer to Table 3 for the total number and percentage of photographs taken in each theme and sub-theme.

Most people photos were of family members ( $\mathrm{N}=$ $410 ; 86 \%)$. The most frequent family member photographed was the young person with the DD ( $\mathrm{N}=163 ; 40 \%)$, followed by TDS ( $\mathrm{N}=101 ; 25 \%)$; mixed groups of family members $(\mathrm{N}=44 ; 11 \%)$; parents $(\mathrm{N}=43 ; 10 \%)$; the sibling him/herself $(\mathrm{N}=$ $32 ; 8 \%)$; and extended family members $(\mathrm{N}=27$; $7 \%)$.

When talking about photographs of the youth with DD, participants either described the young person's characteristics or mentioned why the young person was important. For example, the 11-yearold sister of a young person with ASD said, ". . . she's very lonely all the time... because she doesn't really understand the stuff that we do." The 9-year-old brother of a young person with DS said, "Without him I wouldn't know a lot of things, and I wouldn't be able to go to a lot of things ... and without him, I don't know what l'd do."

Table 3: Photograph Analysis

\begin{tabular}{|c|c|c|c|c|c|}
\hline Theme/Sub Theme & $\begin{array}{l}\text { Total } \\
\text { N (\%) }\end{array}$ & $\begin{array}{c}\text { Female } \\
\text { Siblings } \\
(N=15) \dagger \\
N(\%)\end{array}$ & $\begin{array}{c}\text { Male } \\
\text { Siblings } \\
(\mathbf{N}=15) \dagger \\
N(\%)\end{array}$ & $\begin{array}{c}\text { Siblings of } \\
\text { YWASD* } \\
\quad \mathrm{N}=14 \\
\mathrm{~N}(\%)\end{array}$ & $\begin{array}{c}\text { Siblings of } \\
\text { YWDS } \\
\text { N=16 } \\
N(\%)\end{array}$ \\
\hline People & $475(67)$ & $280(81)$ & $195(55)$ & $186(56)$ & $289(78)$ \\
\hline Family & $410(86)$ & $227(81)$ & $183(94)$ & $164(88)$ & $246(85)$ \\
\hline YWDD & $163(40)$ & $92(41)$ & $71(39)$ & $48(29)$ & $115(47)$ \\
\hline $\operatorname{TDS}^{* * * *}$ & $101(25)$ & $62(27)$ & $39(21)$ & $46(28)$ & $55(23)$ \\
\hline Mixed & $44(11)$ & $29(13)$ & $15(8)$ & $15(9)$ & $29(12)$ \\
\hline Self & $32(8)$ & $14(6)$ & $18(10)$ & $9(5)$ & $23(9)$ \\
\hline Parents & $43(10)$ & $16(7)$ & $27(15)$ & $24(15)$ & $19(8)$ \\
\hline Extended family & $27(7)$ & $14(6)$ & $13(7)$ & $22(13)$ & $5(2)$ \\
\hline Non-family & $65(14)$ & $53(19)$ & $12(7)$ & $22(11)$ & $43(15$ \\
\hline Non-people & $229(33)$ & $69(19)$ & $160(45)$ & $147(44)$ & $82(22)$ \\
\hline Objects & $129(56)$ & $35(51)$ & $94(49)$ & $88(60)$ & $41(50)$ \\
\hline Animals & $51(22)$ & $12(17)$ & $39(24)$ & $29(20)$ & $22(27)$ \\
\hline Buildings/scenery & $49(21)$ & $22(32)$ & $27(17)$ & $30(20)$ & $19(23)$ \\
\hline Total & $704(100)$ & $349(50)$ & $355(50)$ & $333(47)$ & $371(53)$ \\
\hline
\end{tabular}

* Youth with Autism Spectrum Disorder.

** Youth with Down syndrome.

*** Youth with a developmental disability.

**** Typically developing sibling.

† Statistically significant inequalities are bolded. 
The second most frequently photographed family member was TDS. These family members were photographed because of the relationship with participants or their characteristics, demonstrated by an 11-year-old brother of a young person with ASD who said, ". . . he just makes me so happy." The teenage brother of a young person with DS said, He (the TDS) likes to spend time with her (youth with DS). Mixed groups of immediate family members (brothers, sisters, parents) were the third most frequent subject of photographs. Participants noted this group was important because they helped/loved the sibling, and participated in activities together. For example, the 13-year-old sister of a youth with ASD said of a photo of her mother and brother, "and this is my mom and $\mathrm{N}$ (brother). I like to take pictures of $\mathrm{N}$ because he's cute." The 9-year-old brother of a young person with DS noted when describing a photograph of his immediate family, "I like my family because if I didn't have them, then I probably wouldn't be here right now . . . and I love them a lot."

The fourth most common family subjects photographed were parents. Mothers and fathers were important because of their relationships with participants or because of what parents did for them. For example, an 8-year-old brother of a young person with ASD said ". . . He's my father and he takes me places like Yellowstone." The 13-yearold sister of a young person with DS said of her mother, ". . . she's one of my best friends. She's the one that I can talk to the most."

Snapshots taken by participants of themselves were the next most frequent family member photographed. When asked why these photographs were taken, one 8-year-old brother of a youth with ASD said, ". . . because it's me . . . because if I wasn't here I wouldn't be important." The 11-yearold brother of a young person with ASD noted, "I was taking a picture of myself. It was kind of hard. But, cause I'm pretty important to myself."

The least frequent family subjects photographed were extended family members including cousins, aunts, uncles, and/or grandparents. The 9-yearold sister of a young person with ASD stated, "I like my uncle a lot . . . because he'll help you with stuff you need and give you shoulder rides and things." An 11-year-old brother of a young person with ASD said about his grandparents, "because I love them and they're just really important to me." When describing the photograph of her cousin, the 10-year-old sister of a young person with DS said, "she's like one of my best friends."

The non-family snapshots $(14 \%$ of people photographs; $N=65$ ), included participants' teachers, therapists, neighbors, or friends. These non-family members were seen as important, because ". . . she always helps me" (9-year-old sister of a young person with ASD talking about a snapshot of her friend). The 9-year-old sister of a young person with ASD, when talking about snapshots of neighbors said, " . . . they mean a lot cuz they always help you out . . . they don't yell at you or anything." The 7-year-old sister of a young person with DS said of a snapshot of her teacher, "why it's important to me is without a teacher you couldn't learn."

Thirty-three percent of photographs taken by siblings of youth with DD did not contain people. The subjects of the non-people photographs were personal items/objects, including posters, athletic equipment, cars, household items, CDs, books, and toys ( $\mathrm{N}=129 ; 56 \%)$; animals including dogs, cats, horses, ducks, turtles, and fish ( $\mathrm{N}=51$, $22 \%)$; and buildings/scenery ( $N=49 ; 21 \%)$, including houses, rooms in houses, churches, schools, and scenery.

Personal items/objects were photographed by participants because they had special meaning, were reminders of significant events, showed achievement, or were entertaining. For example, the 8-year-old brother of a young person with ASD said of a wooden box, "This is my treasure chest that my grandpa made me for my birthday." Similarly, the 7-year-old sister of another youth with ASD said, "Because it was one of my first times in skating and I won a trophy ... . and I was really proud of myself." The 10-year-old sister of a young person with DS described her attachment to a photograph of a stuffed animal: "That's my favorite teddy bear. It used to be my brother's so it's really important to me." The 13-year-old sister of a young person with DS mentioned her clogging award certificate, "Because that's one of the things that's important to me." 
When describing participants' snapshots of family pets or domestic animals, the 9-year-old sister of a young person with ASD said, "It's a horse because I love horses." An 11-year-old brother of another young person with ASD said, "That's my dog . . . she's really important and I love her . . . She'd protect our house from other dogs." When asked why the image of his pet was important, the 9-year-old brother of a youth with DS said, "Well, my dog is important because . . . I've like known him ever since I was born and he's a real good friend. He always likes to play with me."

Buildings/scenery photographs were often described as places of learning, living, family togetherness, or scenes of places where participants remembered being. The 9-year-old sister of a child with ASD said of her house: "We can do things as a family." An 11-year-old brother of a young person with ASD said of a snapshot of his school, "it helps me learn; it helped me know pretty much everything that I know." The 7-yearold sister of a young person with DS said of a photograph of the mountains, ". . . once I went hiking in 'em [mountains] and camping."

We used the chi square goodness of fit test to examine similarities between the percentage of photographs sisters and brothers took of people photographs and family photographs. We found the percentages were significantly different. See Table 3. In addition, the percentage of photographs taken by the different age groups of family members compared to the percentage of snapshots they took of non-family members were significantly different. The 7-9-year-olds took a higher percentage of snapshots of TDS and him/herself than the two older age groups. On the other hand, the 10-12-year-olds and the 13-16-year-olds took a higher percentage of photographs of the youth with DD than the younger age group. See Figure 1.

Goodness of fit analyses also revealed inequalities in the percentages of photographs of family members taken according to disability type. Refer to Table 3. Siblings of youth with DS took a higher percentage of snapshots of the youth with DD, TDS, mixed family members, and themselves, whereas siblings of youth with ASD took a higher percentage of photographs of parents and extended family members.

All goodness of fit tests examining the percentages of snapshots taken by the three different age groups according to disability type demonstrated inequalities. (See Table 4).

Table 4: Chi Square; Differences According to Age and Disability Type

\begin{tabular}{|lcccc|}
\hline & $\mathbf{X}^{\mathbf{2}}$ & $\mathbf{d f}$ & $\mathbf{N}$ & $\mathbf{p}$ \\
\hline People/Non-people & 42.7 & 5 & 704 & $<.001$ \\
Family/Non-family & 27.1 & 5 & 475 & $<.001$ \\
Within family & 337 & 25 & 410 & $<.001$ \\
Non-people & 94.9 & 10 & 229 & $<.001$ \\
\hline
\end{tabular}

The highest percentage of 'people' photographs was taken by 10-12-year-old siblings of youth with

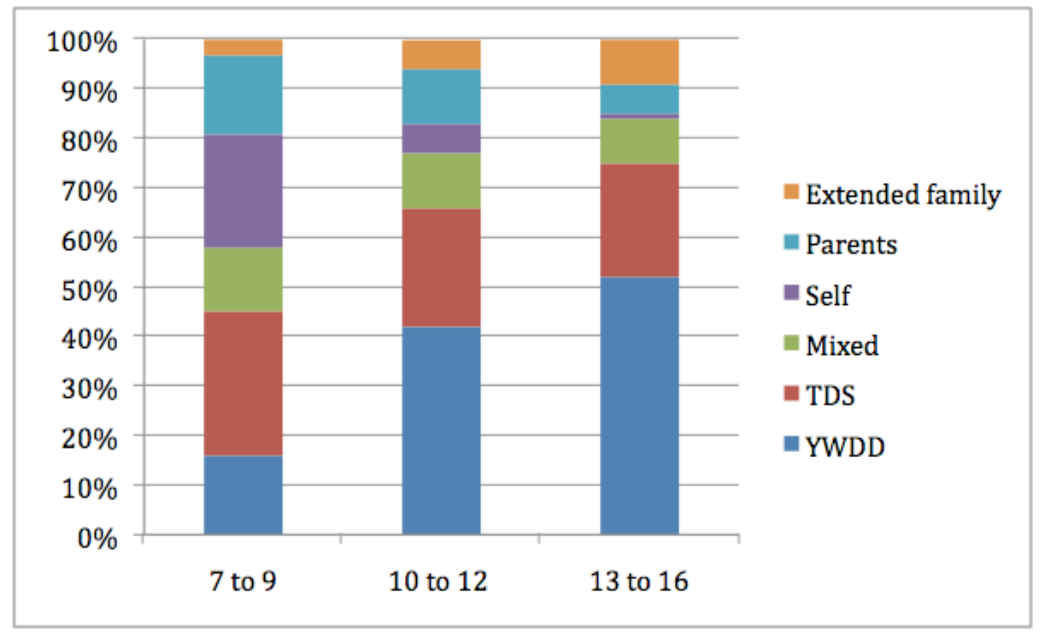

Figure 1. Within family according to age bar chart. 
DS $(82 \%)$, and the highest percentage of 'nonpeople' photographs was taken by 7-9-year-old siblings of youth with ASD (53\%). However, when examining the percentages of photographs taken by each age group of siblings of youth with different DD within the people category, $100 \%$ of photographs taken by 13-16-year-old siblings of youth with ASD were of family members. The highest percentage of photographs taken within the family subcategory was of the youth with the DD, snapped by 13-16-year-old siblings of youth with DS. Refer to Figure 2. When examining snapshots within the non-people category, the 1316 -year-old siblings of youth with ASD took the most photographs of personal items/objects (75\%) See Figure 3.
All goodness of fit analyses examining the percentages of snapshots taken according to gender and disability type found inequalities. Refer to Table $\mathbf{5}$ for the specific chi-square analyses.

Table 5: Chi Square; Differences According to Gender and Disability Type

\begin{tabular}{|lcccc|}
\hline & $\mathbf{X}^{2}$ & $\mathbf{d f}$ & $\mathbf{N}$ & $\mathbf{p}$ \\
\hline People/Non-people & 31.6 & 6 & 704 & $<.001$ \\
Family/Non-family & 214.1 & 3 & 475 & $<.001$ \\
Within family & 55.4 & 15 & 410 & $<.001$ \\
Non-people & 31.6 & 6 & 229 & $<.001$ \\
\hline
\end{tabular}

The highest percentage of people photographs was taken by sisters of youth with DS (83\%); the

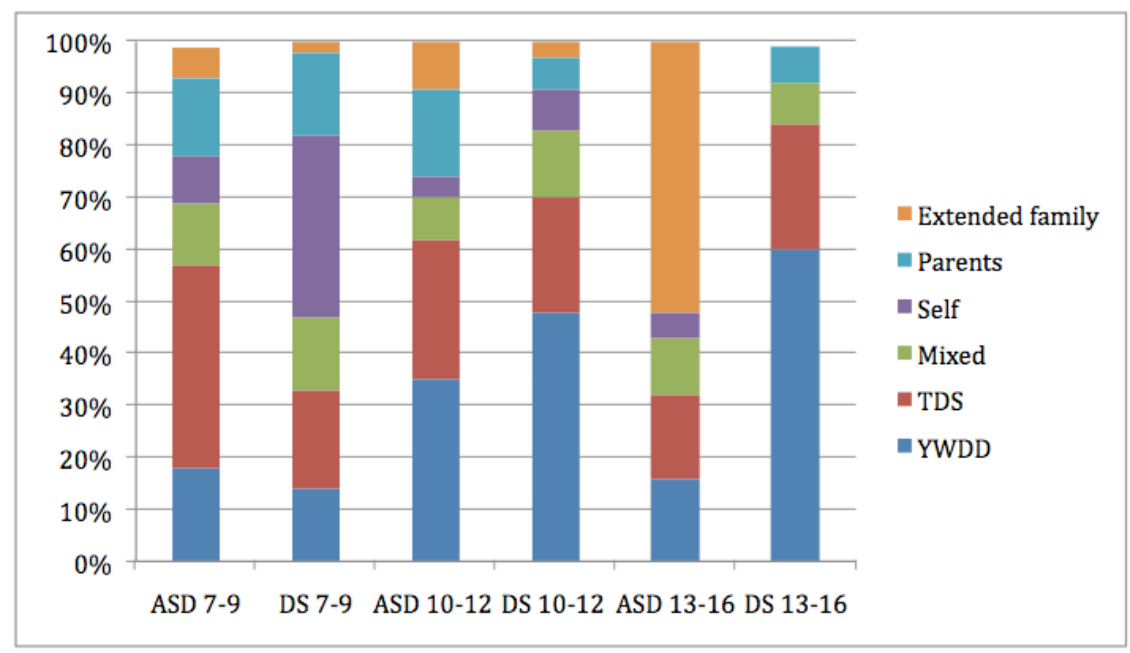

Figure 2. Within family according to age and disability bar chart.

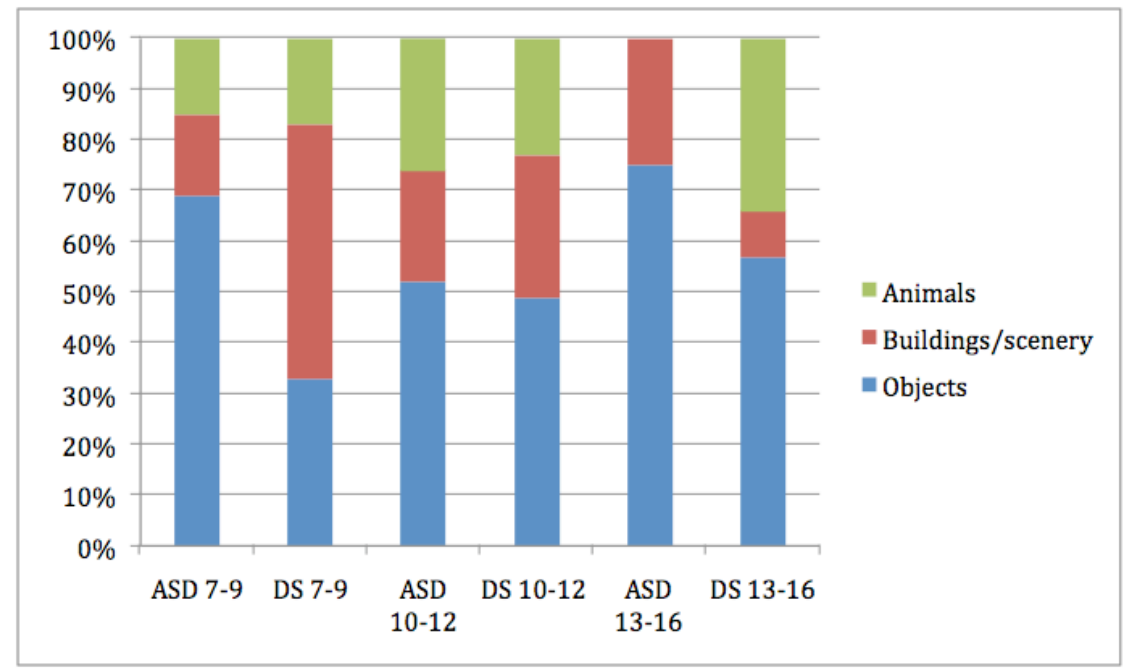

Figure 3. Non people according to age and disability bar chart. 
highest percentage of photographs of non-people was taken by brothers of youth with ASD (53\%). However, when examining the percentages of people photographs taken according to gender and disability, $94 \%$ of photographs taken by brothers of youth with ASD were of family members. On the other hand, the highest percentage of photographs taken within the family was of the youth with the DD, snapped by sisters of youth with DS (48\%). Refer to Figure 4. When examining snapshots of non-people, brothers of youth with ASD took the most photographs of personal items/objects (62\%). Refer to Figure 5.

\section{DISCUSSION}

This project used photo elicitation to determine what was important to siblings of youth with ASD or DS, and if the percentage of photographs taken according to sibling age, gender, and type of disability were equal. Although one study used video cameras to document experiences of siblings of young people with ASD, and other studies used photography to elicit communication with young people about their lives, no other investigators used photo elicitation to compare photographs taken by two different populations such as siblings of youth with ASD or DS [26,31-34,36,69,80,81].

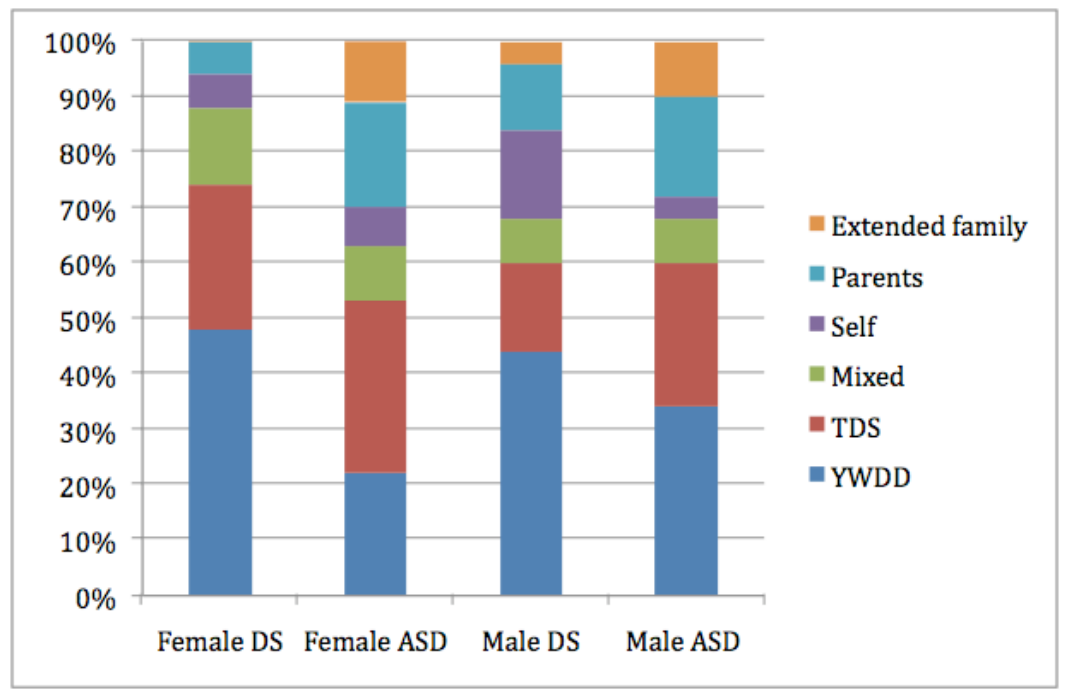

Figure 4. Within family according to gender and disability bar chart.

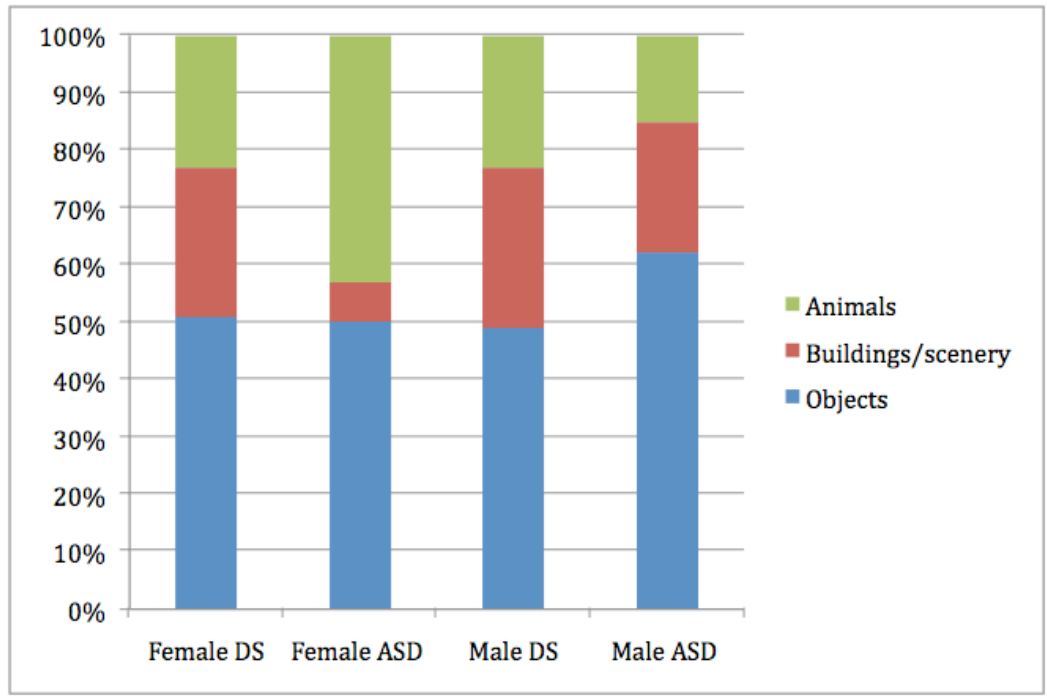

Figure 5. Non people according to gender and disability bar chart. 
In the current study, photographs, considered a record of a person's life, reminded siblings of experiences/people, or allowed them to capture important images [71]. Siblings, were able to use cameras correctly, talked about experiences perhaps not otherwise mentioned, and led the discussion as investigators learned about experiences living with a young person with a DD.

Siblings photographed people, including family and non-family, as well as non-people, including personal items/objects, animals, and buildings/scenery, similar to findings from other research [20-22,43,44]. Additional information about family members or experiences not in photographs also appeared as siblings told investigators what was important about snapshots

Siblings of youth with either disability took a higher percentage of photographs of people compared to non-people. This finding is similar to the distribution of photographs taken by other populations, suggesting people are more important than objects to participants [33,36,75,77-79,81,84-86].

The most common 'people' photographs were family rather than non-family members. These results are similar to other investigators who learned family was more frequently photographed by parents of young people with DD and young people with DD $[79,85]$. Similarly, photographs taken by youth who recorded important consumer items, or those photographing examples of literacy in the home, were also family members, even though participants were not asked to photograph family members [31,32,87]. Reasons participants gave for taking snapshots of family reflected them being loving, helpful, and able to participate in activities. These reasons suggest participants are similar to other young people in their middle school years who often feel families are a source of comfort, nurturing, and emotional support $[89,90]$.

We also discovered the young person with the DD was the most often photographed family member. This is not surprising since on average, youngsters report positive relationships with their siblings, whether or not they have a disability, and compared to siblings growing up with a TDY, siblings of youth with DD report less competition, fewer quarrels, and greater admiration for the youth [41]. Van Riper suggested a young person with a DD may create a growth-producing experience for families and can have a positive influence on family members [12]. Other investigators found siblings admired the young person, were proud of the young person's efforts and achievements, reported positive aspects of living with the youth, and believed time spent together was fun $[6,26,41,91]$. Finally, snapshots may reflect responsibility siblings have in caring for the youth with the DD or feelings of sorrow for the young person with the DD $[15,22]$.

The second most frequent family member photographed was TDS. These family members were also commonly photographed by youth with DD [78]. Brothers and sisters are important to each other, perhaps because of their duration, egalitarian nature, and common cultural milieu. Sibling relationships are often the first, most intense, and longest peer relation an individual will have [92]. They help youth learn sociable and problem behaviors, and provide emotional/physical contact at critical life stages $[93,94]$. These family relationships also allow siblings to express feelings and share ideas as they experience rivalry, support, and loyalty [21].

Fourteen percent of the 'people' photographs were of non-family. These individuals were important to participants based on their interactions and support offered. In fact, the most common photograph taken by preschool children, when asked to photograph what they wanted, was of preschool staff or other preschoolers [33]. Interactions and support offered by non-family members to families of youth with DD are critical. Ekas and colleagues discovered support offered by friends of parents raising youth with DD was helpful in reducing negative effects of raising the young person [95]. Perhaps the same effect occurs with siblings of youth with DD.

Thirty-three percent of photographs taken by participants did not contain people, but were of personal items/objects, animals, or buildings/scenery. This might indicate siblings' attachment to these non-people items or symbolize accomplishments, interests, important events, or significant people. Recording the situation with a photograph may 
help memorialize it [31]. Twice as many personal items were photographed as animals, building/scenery. Similar percentages of photographs were taken by young people with disabilities in a previous study [78].

While both genders of siblings took a higher percentage of photographs of people compared to non-people, sisters took a higher percentage of photographs of people than brothers. This may be because females are often encouraged more than males to assume expressive roles involving being sensitive, nurturing, cooperative, and kind to other people $[98,99]$. The most common people photographed by siblings of both genders were family members. However, brothers took a higher percentage of photographs of family members than sisters did.

There were differences in the percentages of photographs taken by the three age groups of family members. The 7-9-year-olds took a higher percentage of snapshots of TDS than the two older age groups. Younger siblings may have taken more photographs of TDS because they were more available; as this age group may be less likely to be out of the home playing, than older siblings. Finally, this age group is not as independent as other age groups and may be more dependent on TDS for interactions or entertainment than siblings of other age groups.

The younger age group also took a higher percentage of photographs of themselves than the other two age groups, and many were of accomplishments. School-aged children are in Erikson's stage of industry/inferiority and often involved in various hobbies, sports, or academic projects [100]. Since one's self-worth is a product of these activities, these young people may photograph themselves participating in these activities in order to remember their proudest moments. The 10-12year-olds and the 13-16-year-olds took a higher percentage of photographs of the youth with the DD than the youngest age group. These older siblings may assume more responsibility for care or supervision of the youth, than the younger siblings. They may be quite attached psychologically to this youth thus reflecting why participants took such a high percentage of photographs.
There were inequalities in the proportion of photographs taken by siblings of youth with ASD compared to DS. Siblings of youth with DS took a higher percentage of snapshots of the youth with DD, TDS, mixed family members, and themselves, whereas siblings of youth with ASD took a higher percentage of photographs of parents, and extended family members. A possible explanation for this is because youth with DS tend to have better social behaviors and communication skills, allowing for more positive interactions than many youth with ASD, who are often socially isolated, display inappropriate emotional reactions, and exhibit abnormal responses to sensory experiences $[56,91]$.

Interestingly, siblings of youth with ASD took a higher percentage of photographs of parents and extended family members compared to percentages of photographs taken by siblings of youth with DS. Parents were seen as important to this group, and interview data indicated participants took these photographs because of their connection, love, and affection for the parent. Parents play an irreplaceable role in the lives of their children and the parent/child relationship can impact a young person's long-term physical and emotional well-being [101]. The extended family members, which included aunts, uncles, cousins and grandparents, probably were helpful and supportive to the siblings, and indicated their relationships were important.

Inequalities were noted in the percentage of photographs according to age and disability. The 1012 and 13-16-year-olds from both types of disability and the 7-9-year-old siblings living with a youth with DS took a higher percentage of photographs of people compared to non-people. The highest percentage of photographs of people was taken by 10-12-year-old siblings of youth with DS, but all age groups of siblings of youth with DS snapped more photographs of people than did siblings of all ages of youth with ASD. These photographs may reflect siblings' interest in people compared to personal items/objects, animals, or buildings/scenery, and the fact they live with a person whose relationships tends to be more reciprocal than a youth with ASD. Interestingly, all sibling age groups of youth with ASD took a higher per- 
centage of photographs of non-people than siblings of youth with DS. The highest percentage of photographs of non-people was taken by 7-9year-old siblings of youth with ASD. The genetic nature of ASD may suggest these siblings, no matter their age, have a broader autism phenotype, and perhaps indicates they are not as interested in taking photographs of people as siblings of youth with DS [102]. All age groups from both types of disability took a higher percentage of photographs of family compared to non-family. In fact, $100 \%$ of photographs taken by 13-16-yearold siblings of youth with ASD were of family members. Perhaps a higher percentage of family was photographed because of accessibility. The high percentage of family photographs across ages and disability may also reflect connections participants have with family members and their desire to capture these connections with cameras.

When examining the percentage of photographs of family members across ages and disability groups, 13-16-year-old siblings of youth with ASD took the highest percentage of photographs of extended family members compared to the other age groups and no photographs of parents. Extended family may be important to these siblings. Perhaps relationships with parents were strained because these teens were expected to assume extra responsibility caring for the youth with ASD compared to the younger siblings, as well as more household chores [65].

Thirteen to sixteen year-old siblings of youth with DS took no photographs of extended family members or themselves. Extended family may not have been accessible. However, it is interesting these 13-16-year-old siblings and siblings of youth with ASD (who took only $5 \%$ of their family photographs of themselves) took so few snapshots of themselves. Teenagers are in Erikson's stage of identity/role confusion, and according to Elkind, have a sense of their own uniqueness (personal fable) and frequently believe they are important to an imaginary audience $[100,103]$. That is why it is surprising that this age group took so few photographs of themselves.

The highest percentage of photographs taken of family members was of the youth with the DD, snapped by 13-16-year-old siblings of youth with DS. However, when examining the percentage of photographs taken across age and disability groups, it is interesting the percentage of photographs taken of the youth with DD increased with age, except for the 13-16-year-old siblings of youth with ASD, where the percentage of photographs taken (16\%) was almost equal to the percentage of photographs snapped by 7-9-year-old siblings of youth with DS (14\%). The changes in the percentage of photographs taken across age groups may be related to siblings taking more interest in the youth with the DD, having more time to spend with the youth, or being assigned to be more responsible for the youth's care as the sibling got older. The 13-16-year-old siblings of youth with ASD may have taken a lower percentage of photographs of the youth because they did not interact as much with the youth compared to the other age groups due to school activities, work, or the young person's behaviors. Another explanation could be that these siblings may not see the young person as being as important in their lives as other family members. This age group of siblings of youth with ASD may also view the youth as a burden or an embarrassment, and aware of changes made in the family because of the youth's condition.

When examining snapshots of non-people, all age groups of siblings of youth with ASD took a higher percentage of photographs of personal items/ objects compared to all age groups of siblings of youth with DS. As mentioned earlier, this may reflect siblings of youth with ASD as possibly having a broader autism phenotype with autistic symptoms not being clinically significant, but reflected in their greater interest in personal items/objects than siblings of youth with DS [100]. On the other hand, the 7-9-year-old and 10-12-year-old siblings of youth with DS took a higher percentage of buildings/scenery than all ages of siblings of youth with ASD or 13-16-year-old siblings of youth with DS. These differences may mean it is easier for younger siblings of youth with DS to take snapshots of buildings rather than animals or personal items/objects.

Another interesting finding is, as siblings got older, except for 13-16-year-old siblings of youth with 
ASD, (who took no photographs of animals), they took more photographs of animals. Perhaps these participants assumed more responsibility in caring for family pets as they got older, or they became more interested in animals, which were more accessible, and consequently photographed them.

Differences were noted in the percentage of photographs taken according to gender and disability. Brothers of youth with DS and sisters living with young people with ASD or DS took a higher percentage of photographs of people compared to non-people. The highest percentage of people photographs was taken by sisters of youth with DS. It is not surprising sisters took more pictures of people than brothers. As noted before, females tend to assume expressive roles involving sensitivity, nurturance, cooperation, and kindness [98, 99]. However, brothers of youth with DS may have taken more photographs of people than brothers of youth with ASD because they live with a youth who tends to be easier to interact with compared to youth with ASD.

The highest percentage of photographs of nonpeople was taken by brothers of youth with ASD. This may be related to the genetic nature of ASD and how some characteristics of ASD are present in siblings even though not manifested clinically, and brothers' interest in photographing nonpeople (personal items/objects, animals, buildings/scenery). Brothers and sisters living with youth with both types of disability took a higher percentage of photographs of family compared to non-family. However, the highest percentage of snapshots was taken by brothers $193 \%$ of photographs taken by brothers of youth with DS and $94 \%$ of photographs taken by brothers of youth with ASD). These siblings see their family as important; however, reasons why brothers took such a high percentage of photographs of their families requires more investigation.

Sisters of youth with ASD or DS took a higher percentage of photographs of non-family than did brothers. This might indicate sisters are more broadly connected to people outside the family including friends or other adults than brothers. It may also reflect their view of peers as close friends, whose relationships tend to be intimate and characteristically involve exchanges of emotional support and self-disclosure [104].

The highest percentage of photographs taken of family members was the young person with DD, taken by brothers and sisters of youth with DS and brothers of youth with ASD, with the highest percentage taken by sisters of youth with DS. Siblings of youth with DS may have taken high percentages of this young person because youth with DS tend to have better social behavior and communication skills and be better behaved, allowing for positive and more frequent sibling interactions [56]. In addition, these youth may have been easier to capture on photographs and more willing to pose compared to youth with ASD. The highest percentage of photographs taken by brothers of youth with ASD (34\%) were of the youth with $A S D$, and the highest percentage of photographs taken by sisters of youth with ASD (31\%) were of TDS. Siblings view the TDS and the youth with ASD as important family members, reflecting the connection and support siblings have with one another.

Male and female siblings of youth with ASD took a higher percentage of photographs of personal items/objects than did brothers and sisters of youth with DS. This may again reflect characteristics of the broader autism spectrum regarding fixation with personal items/objects [105]. However, siblings of youth with DS may be more focused on people because they live with a young person with DS who is often affectionate and positive in relations with others [54-56].

We noted at least six study limitations. First, there were no safeguards to prevent parents from suggesting which photographs siblings should or should not take, even though they were encouraged to let participants photograph whatever they wanted. Second, siblings may have forgotten to take snapshots while they had cameras, or wanted to take photographs of something important, but cameras were not available. Third, participants were fairly homogeneous; families were middle class, Caucasian, lived in the same urban area, and parents were well-educated. Fourth, perhaps because they did not know the investigators well, or because of their developmental level, 
younger siblings sometimes had difficulty articulating why images were important. Fifth, there was no information as to the levels of impairment the youth with DD experienced, which may have influenced the kind of photographs participants took. Lastly, differences between the age of participants and the youth with the DD; birth order of participants and youth; or the number of other children/adolescents in the family could have effected results.

Recommendations for further research include using different qualitative methods (e.g., diaries, open-ended questions, drawings, video cameras) and then comparing analyses across methods. Future research may also consider using siblings living with youth experiencing a variety of chronic conditions/disabilities or raising only TDY from different geographic areas, ethnic groups, or socioeconomic classes so comparisons are possible. We are just beginning to learn about sibling experiences when they live with a young person with a DD, and obtaining data about their lives using a variety of different methods is important [106].

We have learned much from this study. First, we learned there are differences in what siblings photographed according to age, gender and disability reflecting what is important in their lives. All ages of siblings and siblings of both gender see people, and specifically family, as more important than non-people or non-family. Therefore, healthcare professionals need to learn more from youth who seem to have challenges interacting with people or family so they might improve those interactions. However, we also learned siblings see TDS and the youth with the DD as important and as a valuable part of their lives, and those relationships should be encouraged. Although non-family were not photographed as much as family, especially for brothers, interactions with non-family should be encouraged as these individuals might provide support not always available for families raising young people with a DD. We also learned siblings of youth with ASD, and more commonly brothers of these youth view non-people and especially personal items/objects as important in their lives. This may reflect siblings' greater interest in personal items/objects than people, as is common in those with $A S D$, and if combined with other signs of ASD may need further evaluation for ASD.

\section{CONCLUSION}

From this study, professionals are reminded siblings' perspectives of their lived experience may not be the same as what adults report. Photo elicitation, one of many qualitative methods, can be valuable in filling a gap in the literature regarding siblings' experiences, and obtaining their perspectives. It may also be an intervention itself, since sometimes having an adult interested in what is said by young research participants is beneficial. Indeed, an effective method of understanding participants' lives enriching other methods and applied across different populations is photo elicitation. Photo elicitation also allows insights into participants' lives, and captures memories discussed later during interviews. Siblings' perspective of living with a young person with ASD or DS is important, and photo elicitation is an appropriate method for gathering information not obtained through other means.

\section{ACKNOWLEDGEMENT}

This project was funded by the College of Nursing, the Family Studies Center, the Office of Research and Creativity, and the Marjorie Pay Hinckley Chair at Brigham Young University, Provo, Utah.

\section{REFERENCES}

[1] O'Brien IO, Duffy A, Nicholl H. Impact of childhood chronic illnesses on siblings: A literature review. Br J Nurs 2009; 18: 1358-65.

[2] Pelchat D, Lefebvre H, Levert MJ. Gender differences and similarities in the experience of parenting a child with a health problem: Current state of knowledge. J Child Health Care 2007; 112-31.

[3] Epstein T, Saltzman-Benaiah J, O'Hare A, Goll JC, Tuck S. Associated features of Asperger syndrome and their relationship to parenting stress. J Child Health Care 2008; 34(4): 503-11.

[4] Mascha K, Boucher J. Preliminary investigation of a qualitative method of examining siblings' experiences of living with a child with ASD. $\mathrm{Br} J$ Dev Disabil 2006; 52: 19-28.

[5] Orsmond GI, Seltzer MM. Siblings of individuals with autism spectrum disorders across the life span. Ment Retard Dev Disabil Res Rev 2007; 13: 313-320. 
[6] Petalas MA, Hastings RP, Nash S, Dowey A, Reilly D. "I like that he always shows who he is": The perceptions and experiences of siblings with a brother with autism spectrum disorder. Intl $\mathrm{J}$ Disabil Dev Educ 2009; 56: 381-99.

[7] Pollard CA, Barry CM, Freedman BH, Kotchick BA. Relationship quality as a moderator of anxiety in siblings of children diagnosed with autism spectrum disorders or Down syndrome. J Child Fam Stud 2013; 22: 647-57.

[8] Rivers JW, Stoneman Z. Sibling relationships when a child has autism: Marital stress and support coping. J Autism Dev Disord 2003; 33: 38394.

[9] Smith LO, Elder JH. Siblings and family environments of persons with autism spectrum disorder: A review of the literature. J Child Adolesc Psychiatr Ment Health Nurs 201; 23: 189-95.

[10] Lobato DJ, Kao BT, Plante W. SibLink: Meeting the needs of siblings of children with chronic illness and disability. The Brown University Child and Adolescent Behavior Letter 2006; 22: 1-6.

[11] Petalas MA, Hastings RP, Nash S, Lloyd T, Dowey A. Emotional and behavioral adjustment in siblings of children with intellectual disability with and without autism. Autism 2009; 13: 47183.

[12] Van Riper M. Family variables associated with well-being in siblings of children with Down syndrome. J Fam Nurs 2000; 6: 267-86.

[13] Graff C, Mandleco BL, Dyches TT, Coverston C, Roper SO, Freeborn D. Perspectives of adolescent siblings of children with Down syndrome who have multiple health problems J Fam Nurs 2012; 18: 175-99.

[14] Skotko BG, Levine SP. What the other children are thinking: Brothers and sisters of persons with Down syndrome Am J Med Genet Part C (Seminars in Medical Genetics) 2006; 142: 180-6.

[15] Barak-Levy Y, Goldstein E, Weinstock M. Adjustment characteristics of healthy siblings of children with autism. J Child Fam Stud 2010; 16: 155-64.

[16] Gamliel I, Yirmiya N, Jaffe D, Manor O, Sigman M. Developmental trajectories in siblings of children with autism: Cognition and language from 4 Months to 7 Years. J Autism Dev Disord 2009; 39: 1131-44.

[17] Ross P, Cuskelly M. Adjustment, sibling problems and coping strategies of brothers and sisters with autistic spectrum disorder. J Intellect Dev Disabil 2006; 31: 77-86.

[18] Stone WL, McMahon CR, Yoder PJ, Walden TA. Early social-communicative and cognitive development of younger siblings of children with autism spectrum disorders. Arch Pediatr Adolesc Med 2007; 161: 384-90.

[19] Hastings RP. Longitudinal relationships between sibling behavioral adjustment and behavioral problems of children with developmental disabilities. J Autism Dev Disord 2007; 37: 1485-92.

[20] Macks RJ, Reeve RE. The adjustment of nondisabled siblings of children with autism. J Autism Dev Disord 2007; 37: 1060-7.

[21] Verté S, Roeyers H, Buyesse A. Behavioural problems, social competence and self-concept in siblings of children with autism. Child Care Health Dev 2003; 29: 193-205.

[22] Benderix Y, Sivberg B. Siblings' experiences of having a brother or sister with autism and mental retardation: A case study of 14 siblings from five families. J Pediatr Nurs 2007; 22: 410-8.

[23] Hema DA, Roper SF, Nehring JW, Mandleco BL, Dyches TT. Daily stressors of children and adolescents with type 1 diabetes. Child Care Health Dev, 2009; 35: 330-9.

[24] Docherty S, Sandelowski M. Focus on qualitative methods: Interviewing children. Res Nurs Health 1999; 22: 177-85.

[25] Cox AH, Marshall ES, Mandleco BL, Olson SF. Coping responses to daily life stressors of children who have a sibling with a disability. J Fam Nurs 2003; 9: 397-413.

[26] Hwang SK, Charnley H. Making the familiar strange and making the strange familiar: Understanding Korean children's experience living with an autistic sibling. Disabil Soc 2010; 25: 579-92.

[27] Sage KD, Jegatheesan B. Perceptions of siblings with autism and relationships with them: European American and Asian American siblings draw and tell. J Intellect Dev Disabil 2010; 35: 92-103.

[28] Rampton TB, Rosemann JL, Latta AL, Mandleco BL Dyches TT, Olsen SF. Images of life: Siblings of children with Down syndrome. J Fam Nurs 2007; 13: 420-42.

[29] Latta AL, Rampton TB, Rosemann JL, et al. Snapshots reflecting the lives of siblings of children with autism spectrum disorder. Child Care Health Dev 2013; 40: 515-24.

[30] Banister E, Booth G. Exploring innovative methodologies for child-centric consumer research. Qual Mark Res: Int J 2006; 8: 157-75.

[31] Croghan R, Griffin C, Hunter J, Phoenix A. Young people's construction of self: Notes on the use and analysis of photo-elicitation methods. Int J Soc Res Methodol 2008; 11: 345-56.

[32] Dickie J, McDonald G. Literacy in church and family sites through the eyes of Samoan children in New Zealand. Literacy 2011; 4: 25-31. 
[33] Einarsdottir J. Playschool in pictures: Children's photographs as a research method. Early Child Dev Care 2005; 175: 523-41.

[34] Guerrero A, Tinkler T. Refugee and displaced youth negotiating imagined and lived identities in a photograph-based educational project in the United States and Colombia. Anthropol Educ Q 2010; 41: 55-74.

[35] Newman M, Woodcock A, Dunham P. Playtime in the borderlands: Children's representations of school, gender and bullying through photographs and interviews. Child Geog J 2006; 4: 289-302.

[36] White A, Bushin N, Carpena-Mendez F, Laoire C. Using visual methodologies to explore contemporary Irish childhood. Qual Res 2010; 10: 143-58.

[37] Dyches TT, Drew C. Autism Spectrum Disorders. In: Hardman ML, Drew CJ, Egan MW, editors. Human exceptionality: School, community, and family. 11th ed. Boston: Cengage Learning; 2013, p 266-95.

38] National Institute of Mental Health. What Are the Autism Spectrum Disorders? 2013 [cited 2015 June 9]: Available from http://www.nimh.nih.gov/ health/topics/autism-spectrum-disorders-pervasiv e-developmental-disorders/index.shtml\#part3

[39] Rhea $P$, Orlovski M, Marchino H, Volkmar F. Conversational behaviors in youth with highfunctioning ASD and Asperger syndrome. J Autism Dev Disord 2009; 39: 115-25.

[40] Tiegerman-Farber E. Autism spectrum disorders: Learning to communicate. In Bernstein DK, Tiegerman-Farber E, editors. Language and communication disorders in children. 6th ed. Boston: Allyn and Bacon; 2009. p. 314-69.

[41] Kaminsky L, Dewey D. Sibling relationships of children with autism. J Autism Dev Disord 2001; 31: 399-410.

[42] Higgins D, Bailey S, Pearce J. Factors associated with functioning style and coping strategies of families with a child with autism spectrum disorder. Autism 2005; 9: 125-37.

[43] Kaminsky L, Dewey D. Psychosocial adjustment in siblings of children with autism. J Psychol Psychiatry 2002; 43: 225-32.

[44] Pilowsky T, Yirmiya N, Doopelt O, Gross-Tsur V, Shalev R. Social and emotional adjustment of siblings of children with autism. J Child Psychol Psychiatry 2004; 45: 855-65.

[45] Moyson T, Roeyers H. The quality of life of siblings of children with autism spectrum disorder Except Child 2011; 78: 41-55.

[46] Opperman S, Alante E. The coping responses of the adolescent siblings of children with severe disabilities. Disabil Rehab 2003; 25: 441-54.
[47] Orsmond GI, Kuo H, Seltzer MM. Siblings of individuals with an autism spectrum disorder: Sibling relationships and wellbeing in adolescence and adulthood. Autism 2009; 13: 59-78.

[48] Hastings RP. Brief report: Behavioral adjustment of siblings of children with autism. J Autism Dev Disord 2003; 33: 99-104.

[49] Meyer KA, Ingersoll B, Hambrick DZ. Factors influencing adjustment in siblings of children with autism spectrum disorders. Res Autism Spectr Disord 2011; 5: 1413-20.

[50] Mavropoulou S, Baloyianni N. Siblings of persons in the spectrum of autism: Exploring their concerns and supporting their needs. Proceedings of the $8^{\text {th }}$ International Conference of Autism Europe; 2007: Oslo, Norway. [cited 2015 June 9]. Available from http://www.academia.edu/1619058/Siblings_of_persons_in_the_spectrum_of_ autism_=Exploring_their_concerns_and_supporti ng_their_needs._Proceedings_of_the_8th International_Conference_Autism_Europe; Oslo

[51] National Down syndrome Society. About Down syndrome: Down syndrome fact sheet. 2014. [cited 2015 June 9]. Available from http://www. ndss.org/Down-Syndrome/Down-SyndromeFacts/

[52] Buckley SJ, Bird G, Sacks B. Social development for individuals with Down syndrome - An overview. 2002 [cited 2015 June 9]: Available from http://www.down-syndrome.org/information/ social/overview/?page $=1$

[53] Ferri F. Ferri's clinical advisor: Instant diagnosis and treatment. Philadelphia, PA: Mosby Elsevier; 2009.

[54] Batshaw ML, Towbin KE. The origins of autism Research News. Ped Res 2001; 50: 1-2.

[55] Cohen WI, Nadel L, Madnick ME. Down syndrome: Visions for the $21^{\text {st }}$ century. New York: Wiley-Liss; 2002.

[56] Stores R, Stores G, Fellows B, Buckley S. Daytime behaviour problems and maternal stress in children with Down's syndrome, their siblings, and non-intellectually disabled and other intellectually disabled peers. J Intellect Disabil Res 1998; 42: 228-37.

[57] Eisenhower AS, Baker BL, Blacher J. Preschool children with intellectual disability: Syndrome specificity, behaviour problems, and maternal well-being. J Intellect Disabil Res 2005; 49: 65771.

[58] Blacher J, McIntyre LL. Syndrome specificity and behavioural disorders in young adults with intellectual disability: Cultural differences in family impact. J Intellect Disabil Res 2006; 50: 184-98.

[59] Boström PK, Broberg M, Bodin L. Child's positive and negative impacts on parents--a person- 
oriented approach to understanding temperament in preschool children with intellectual disabilities. Res Dev Disabil 2011; 32(5): 1860-71.

[60] Bhattacharya M, Sidebotham P. Parental and professional perceptions of the levels of disability in children with Down's syndrome. Amb Child Health 2000; 6: 153-63.

[61] Hassold TJ, Patterson D. Down syndrome: A Promising Future, Together. New York: Wiley; 1999.

[62] Cuskelly M, Gunn P. Maternal reports of behavior of siblings of children with Down syndrome. Am J Ment Retard 1993; 97: 521-9.

[63] McHale SM, Gamble WC. Sibling relationships of children with disabled and nondisabled brothers and sisters. Dev Psychol 1989; 25: 421-9.

[64] Fleitas J. When Jack fell down . . .Jill came tumbling after: Siblings in the web of illness and disability. MCN Am J Matern Child Nurs 2000; 25 : 267-73.

[65] Rossiter L, Sharpe D. The siblings of individuals with mental retardation: A quantitative integration of the literature. J Child Fam Stud 2001; 10: 6584.

[66] Hodapp RM. Families of persons with Down syndrome: New perspectives, findings, and research and service needs. Ment Retard Dev Disabil Res Rev 2007; 13: 279-87.

[67] Skotko BG, Levine SP, Goldstein R. Having a brother or sister with Down syndrome: Perspectives from siblings. Am J Med Genet Part A 2011; 155: 2348-59

[68] Baumann SL, Dyches TT, Braddick M. Being a sibling. Nurs Sci Quart 2005; 18: 51-8.

[69] Drew SE Duncan RE, Sawyer SM. Visual storytelling: A beneficial but challenging method for health research with young people. Qual Health Res 2010; 20: 1677-88.

[70] Riley RG, Manias E. The uses of photography in cylindrical nursing practice and research: A literature review. J Adv Nurs 2004; 48: 397-405.

[71] Sontag S. On photography. New York: Farrar Straus Giroux; 1977.

[72] Samuels J. Breaking the ethnographer's frames. Reflections on the use of photo elicitation in understanding Sri Lankan monastic culture. Am Behav Sci 2004; 47: 1528-50.

[73] Cappello M. Photo interviews: Eliciting data through conversations with children. Field Methods 2005; 17: 170-82.

[74] Clark-lbanez M. Framing the social world with photo-elicitation interviews. Am Behav Sci 2004; 47: 1507-27.

[75] Hanna KM, Jacobs PM, Guthrie D. Exploring the concept of health among adolescents with diabe- tes using photography. J Pediatr Nurs 1995; 10: 321-7.

[76] Aitken SC, Wingate J. A preliminary study of the self-directed photography of middle-class, homeless, and mobility-impaired children. SelfDirected Photog 1993; 45: 65-72.

[77] Hanna KM, Jacobs PM. The use of photography to explore the meaning of health among adolescents with cancer. Issues Compr Pediatr Nurs 1993; 16: 155-64.

[78] Dyches TT, Chichella E, Olsen SF, Mandleco BL. Snapshots of life: Perspectives of school-aged individuals with developmental disabilities. Res Pract Persons Severe Disabl 2004; 29: 172-82.

[79] Percy MS. Children from homeless families describe what is special in their lives. Holist Nurs Pract 1995; 9: 24-33.

[80] Bruce BS, Ungar M, Waschbusch DA. Perceptions of risk among children with and without attention deficit/hyperactivity disorder. Int $\mathrm{J}$ Inj Contr Saf Promot 2009; 16: 189-96.

[81] Thupayagale-Tshweneagae G, Benedict A. The burden of secrecy among South African adolescents orphaned by HIVIAIDS. Issues Ment Health Nurs 2011; 32: 355-8.

[82] Piaget J. The Origins of Intelligence in Children. New York: Norton; 1963.

[83] Vygotsky LS. Thought and Language. Cambridge MA: MIT Press; 1962

[84] Glover-Graf NM. Student-produced photography: A constructivist approach to teaching psychosocial aspects of disability. Rehabil Ed 2000; 14: 285-96.

[85] Lassetter JH, Mandleco BL, Roper SO. Family photographs: Expressions of parents raising children with disabilities. Qual Health Res 2007; 17: 456-67.

[86] Berman H, Ford-Gilboe M, Moutrey B, Cekic S. Portraits of pain and promise: A photographic study of Bosnian youth. Can J Nurs Res 2001; 32: 21-41.

[87] Lorenz L, Kolb B. Involving the public through participatory visual research methods. Health Expect 2009; 12: 262-274.

[88] Moss G. Seeing with the camera: Analyzing children's photographs of literacy in the home. J Res Read 2001; 24: 279-92.

[89] Daversa F. The importance of family. 2014. [cited 2015 June 9].Available from http://www. frankdaversa.com/the-importance-of-family/

[90] Angell ME, Meadan H, Stoner JB. Experiences of siblings of individuals with autism spectrum disorders. Autism Res Treat 2012; 1-11.

[91] Petalas MA, Hastings RP, Nash S, Reilly D, Dowey $A$. The perceptions and experiences of 
adolescent siblings who have a brother with autism spectrum disorder. J Intellect Dev Disabil 2012; 37: 303-14.

[92] Powell TH, Gallagher PA. Brothers and sisters: A special part of exceptional families, 2nd ed. Baltimore: Paul H Brookes; 1993.

[93] Martin JL, Ross HS. The development of aggression within sibling conflict. Early Educ Dev. 1995; 6: 335-58.

[94] Stormshak EA, Bellanti CJ, Bierman KL. The quality of sibling relationship and the development of social competence and behavioral control in aggressive children. Dev Psychol 1996; 32: 79-89.

[95] Ekas NV, Lickenbrock DM, Whitman TL. Optimism, social support, and well-being in mothers of children with autism spectrum disorder. J Autism Dev Disord 2010; 40: 1274-84.

[96] Melson GF. Child development and the humancompanion animal bond. Am Behav Sci 2003; 47: 31-9.

[97] Spence LJ, Kaiser L. Companion animals and adaptation in chronically ill children. West J Nurs Res 2002; 24: 639-56.

[98] Sigelman CK, Rider EA. Life-span human development. 8th ed. Independence, KY: Cengage Learning; 2015.
[99] Shaffer, DR. Social and personality development. 6 th ed. Independence, KY: Cengage Learning; 2008.

[100] Erikson EH. Identity: Youth and crisis. Norton, New York; 1968.

[101] Shaw BA, Krause N, Chatters LM, Connell CM, Ingersoll-Dayton B. Emotional support from parents early in life, aging, and health. Psychol Aging 2004; 19: 4-12.

[102] Gerdts J, Bernier R. The broader autism phenotype and its implications on the etiology and treatment of autism spectrum disorders. 2011; [cited 2015 June 9] Available from: http://www. hindawi.com/journals/aurt/2011/545901/\#B9

[103] Elkind D. Egocentrism in adolescence. Child Dev 1967; 3: 1025-1034.

[104] Bee H, Boyd DA. Lifespan development, $7^{\text {th }}$ ed. Upper Saddle River, N.J: Pearson Education; 2015.

[105] Allen PJ, Vessey JA, Schapiro N. Primary Care of the Child with a Chronic Condition, $5^{\text {th }}$ ed. St. Louis: Mosby; 2010.

[106] Ferraioli SJ, Harris SL. The impact of autism on siblings. Soc Work Ment Health 2010; 8: 41-53. 